\title{
Blood pressure variability in patients with atrial fibrillation
}

\author{
Valentina D.A. Corino ${ }^{\text {a,* }}$, Federico Lombardi ${ }^{\text {b }}$, Luca T. Mainardi ${ }^{\text {a }}$ \\ a Dipartimento di Elettronica, Informatica e Bioingegneria, Politecnico di Milano, via Golgi 32, 20133 Milan, Italy \\ ${ }^{\mathrm{b}}$ U.O.C. di Malattie Cardiovascolari, Fondazione IRCCS “Ca Granda” Ospedale Maggiore Policlinico, Dipartimento di Scienze Cliniche e di Comunità, Università degli Studi di Milano, Milan, \\ Italy
}

Received 15 May 2014

Received in revised form 25 July 2014

Accepted 12 August 2014

\section{Introduction}

Atrial fibrillation (AF) is a common arrhythmia characterized by an irregular ventricular rhythm (Stein et al., 1999), which precludes an appropriate spectral analysis of its variability. In fact, when the RR variability signal is analyzed with spectral techniques, a white noise pattern without any identifiable discrete components along the frequency axis is commonly detected. As a result, very few studies have attempted to describe the presence of rhythmical components in $\mathrm{RR}$ and systolic arterial pressure (SAP) variability in patients with AF. The highly irregular ventricular rate during AF may represent a unique and natural experimental model to eliminate the influence of rhythmical components of RR variability on arterial pressure variability and thus investigate a possible central neural origin of LF component in arterial pressure
Abbreviations: AF, atrial fibrillation; DAP, diastolic arterial pressure; ECG, electrocardiogram; HF, high frequency; LF, low frequency; SAP, systolic arterial pressure.

* Corresponding author at: Dipartimento di Elettronica, Informatica e Bioingegneria, Politecnico di Milano, via Golgi 32, 20133 Milan, Italy. Tel.: + 39022399 3392; fax: + 39 0223993360.

E-mail address: valentina.corino@polimi.it (V.D.A. Corino). variability. It was initially reported (Pitzalis et al., 1999) that a respiratory related HF component of SAP variability could be observed during $\mathrm{AF}$ even in the absence of a respiratory sinus arrhythmia. In the same study, however, no attempt was made to evaluate whether LF oscillations could also be detected. A few years ago, we analyzed the short-term arterial pressure variability before and immediately after restoration of sinus rhythm in patients with persistent AF (Mainardi et al., 2009). The main findings of the study were the observation of LF component of arterial pressure variability during $\mathrm{AF}$, the independence of this component from the presence of a correspondent component in RR variability, and a marked reduction of the power of LF component of arterial pressure variability after recovery of sinus rhythm.

We have recently observed in a small group of patients with AF that the LF and HF components of blood pressure spectrum may be influenced by a sympathetic stimulus, such as the one induced by a tilt-up stress test (Corino et al., 2013).

The aim of the present study was to assess whether the effects on blood pressure variability of sympathetic activation induced by tilt could also be detected in patients with AF: i.e., in a physiological model in which the coupling between cardiac cycle duration and pulse pressure is regulated independently of functioning baroreflex control mechanisms for the lack of an effective autonomic control of sinus node function. 


\section{Materials and methods}

\subsection{Study patients}

We analyzed cardio-respiratory signals from 30 consecutive patients (64 \pm 12 years, 19 males) admitted to the hospital for programmed electrical cardioversion for persistent AF according to international guideline indication (i.e. an AF episode lasting longer than 7 days and requiring termination by electrical cardioversion) (Camm et al., 2010). The mean duration of arrhythmia was $6 \pm 1$ months. Clinical characteristics are shown in Table 1.

The study conforms with the Declaration of Helsinki, and was approved by the Ethics Committee of San Paolo Hospital in Milan (Italy). All patients gave their written informed consent for the procedures related to the study.

\subsection{Study design}

Three orthogonal leads, a periodic reference arterial pressure measurement, continuous beat-to-beat non-invasive recordings of arterial pressure and the respiratory signal were obtained with a Task Force ${ }^{\circledR}$ Monitor (CNSystem; GRAZ, Austria) recording system. The morning be-fore electrical cardioversion, surface ECG and blood pressure signals were acquired at rest and during a passive orthostatic stimulus. Head-up tilt test was performed at $75^{\circ}$, with 10 second time necessary to move from 0 to $75^{\circ}$ or to go back. Both phases lasted about $15 \mathrm{~min}$. The sampling frequency was $1 \mathrm{kHz}$ for the ECG signal and $100 \mathrm{~Hz}$ for continuous arterial pressure recording. Raw data were exported as ASCII text files for off-line analysis.

\subsection{Data processing}

\subsubsection{Series extraction}

2.3.1.1. RR series extraction. An automatic QRS detection algorithm was used to locate $R$ waves on the ECG, and an interactive graphic interface allowed the operator to visually identify and correct misdetected beats. RR intervals were measured as the distance between two consecutive $\mathrm{R}$ waves.

2.3.1.2. Blood pressure series extraction. During normal sinus rhythm, the extraction of beat-to-beat systolic pressure series is commonly performed by searching for a local maximum in the BP signal following

\section{Table 1}

Demographic characteristics and cardiovascular history in the study population and in the two subgroups (group A: patients whose systolic arterial pressure increased during tilt, group B: patients whose systolic arterial pressure did not increase during tilt).

\begin{tabular}{llll}
\hline Variable & All patients & Group A & Group B \\
\hline $\mathrm{N}$ & 30 & 15 & 15 \\
Gender (male/female) & $19 / 11$ & $11 / 4$ & $8 / 7$ \\
Age (years) & $66 \pm 11(38-83)$ & $61 \pm 15$ & $67 \pm 9$ \\
AF duration (months) & $3 \pm 4(2-9)$ & $3 \pm 4(2-9)$ & $3 \pm 4(2-9)$ \\
Previous AF & 16 & 6 & 10 \\
Previous electrical & 14 & 5 & 9 \\
$\quad$ cardioversion & & & \\
Previous myocardial & 3 & 1 & 2 \\
$\quad$ infarction & & & \\
Ejection fraction & $57 \pm 8(35-68)$ & $55 \pm 9(35-63)$ & $60 \pm 6(45-68)$ \\
Left atrium diameter & $46 \pm 7(33-62)$ & $47 \pm 6(38-59)$ & $46 \pm 8(33-62)$ \\
$\quad($ mm) & & & \\
Diabetes & 3 & 1 & 2 \\
Hypertension & 17 & 6 & 11 \\
Beta-blockers & 16 & 8 & 8 \\
Flecainide & 4 & 1 & 3 \\
Cordarone & 6 & 3 & 3 \\
ACE-inhibitor & 17 & 6 & 11 \\
Ca-antagonist & 5 & 4 & 1
\end{tabular}

each R-wave. This approach is inappropriate during AF as $\mathrm{R}$ waves may not be coupled with an adequate left ventricular output to generate discrete pulses in arterial pressure and the QRS's are not necessarily followed by an arterial pressure pulse. For measuring the beat-to-beat systolic values, we applied a method not relying on the information about QRS location (Mainardi et al., 2009). It first coarsely localizes arte-rial pressure systolic peaks and then refines their positions, thus obtaining the systolic values too (see Fig. 1).

An interactive graphic interface allowed the operator to visually identify and correct misdetected arterial pressure pulse events. We also extracted and analyzed DAP series, whose values were defined as the local minimum preceding detected valid systolic value.

Finally, SAP and DAP series were interpolated (using cubic splines) and resampled at $1 \mathrm{~Hz}$ to obtain series with the same length.

\subsubsection{Spectral analysis}

Power spectral analysis was performed on SAP and DAP series by means of an autoregressive model. The coefficients of the autoregressive model were estimated using the Levinson Durbin algorithm; a statistical test (Kay and Marple, 1981) was used to check the validity of the model and the model order was selected by use of the Akaike Information Criterion (Akaike, 1998), starting from a minimum order of 7 up to a maximum order of 20. A spectral decomposition algorithm (Baselli et al., 1987) was used to compute the spectral components and to measure the central frequency and the power, i.e., the area below the spectral peaks, in the low frequency (LF, 0.03-0.15) and high frequency (HF, 0.15-0.40 Hz) bands. An LF (or HF) rhythm is detected if at least one spectral component has its center frequency (related to AR poles position) lying in the band.

\subsubsection{Cross-spectral analysis}

To assess the relations between pressure signals and respiratory signals in the respiratory band, we performed autoregressive bivariate spectral analysis and we used the squared coherence function (K2) to evaluate the phase stability between the oscillations of the two signals (range: 0 , no relation to 1 , close relation) at any frequency.

\subsubsection{Statistical analysis}

The data are given as mean values \pm one SD. The Wilcoxon signed rank test was used to evaluate the differences between parameters at rest and during tilt. A value of $p<0.05$ was considered significant.

\section{Results}

A LF component of arterial pressure variability was evident in almost all patients. In particular, during rest the $0.1 \mathrm{~Hz}$ component was detectable in 27 out of 30 patients in SAP variability and in 23 out of 30 patients in DAP variability. During tilt the LF component was detectable in 28 out of 30 patients in SAP variability and in 25 out of 30 patients in DAP variability. A HF component of arterial pressure variability was present in all patients in DAP variability, and in all but one in SAP variability during both experimental conditions.

Squared coherence revealed a significant coupling between respiratory signal and SAP variability in 9 out of 30 patients $(0.71 \pm 0.12)$ during rest and in 10 out of $30(0.69 \pm 0.16)$ during tilt.

Fig. 2 shows an example of RR, SAP and respiratory signal. The spectrum of RR series presents several peaks which cannot be associated with discrete LF and HF bands. On the other hand, LF and HF components can be easily detected in SAP spectrum, while only HF was visible in the respiratory signal spectrum. Fig. 2(c) and (f) shows the squared coherence function between the respiratory signal and RR and SAP series, respectively. It can be noted that no coherence can be found between respiratory signal and RR series, whereas a significant coherence (i.e., $K^{2}>0.5$ ) is present between respiratory signal and SAP series.

We observed two different patterns of SAP response to orthostatic stimulus. In 15 patients (group A) there was an increase in systolic 
(a)

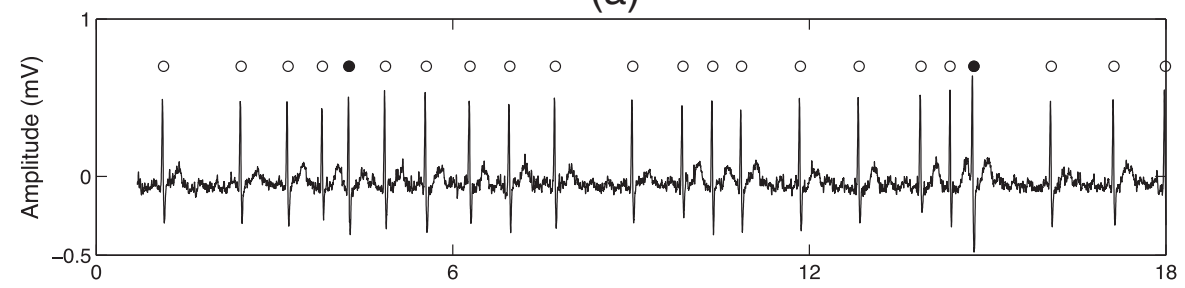

(b)

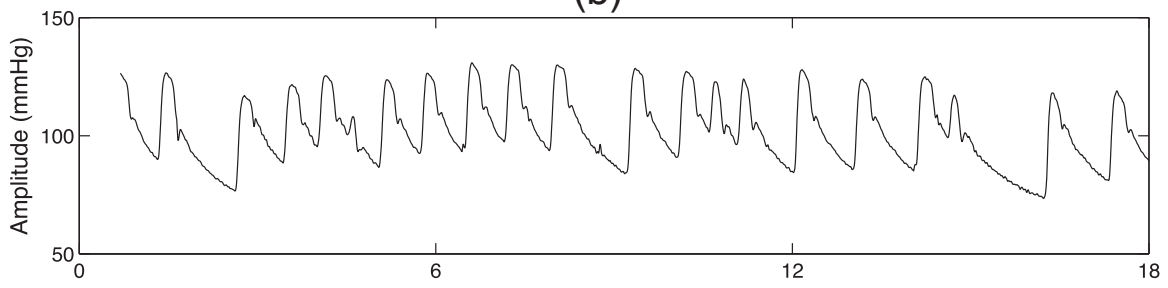

(c)

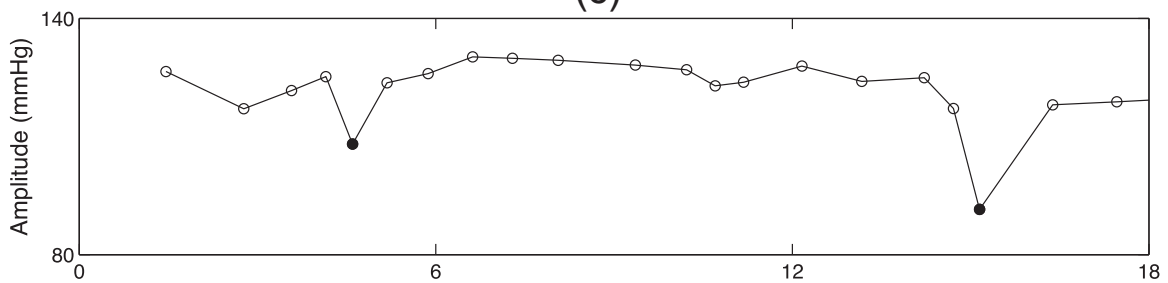

(d)

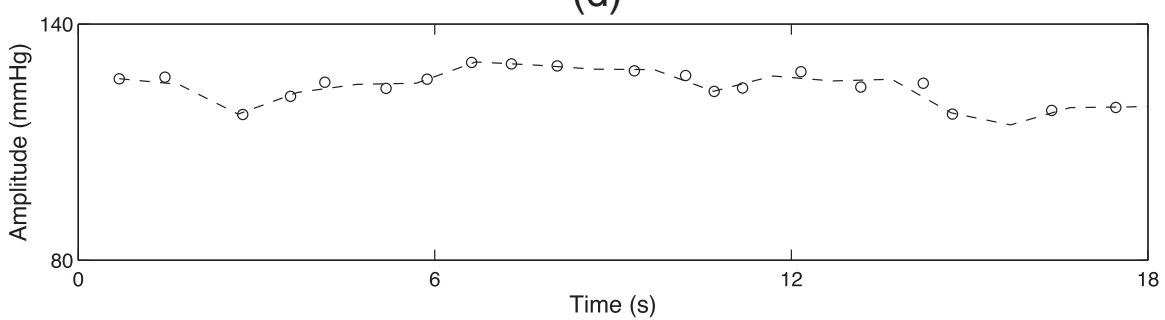

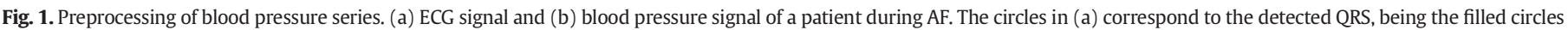

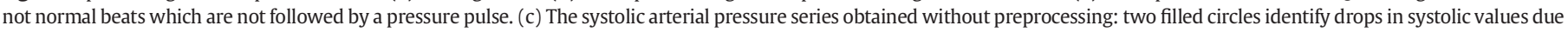
to an insufficient pressure pulse. (d) Circles represent the final systolic arterial pressure values and the dashed line is the series after re-sampling it at $1 \mathrm{~Hz}$.

pressure of at least $5 \mathrm{~mm} \mathrm{Hg}$ during tilt. In these patients systolic pres-sure increased on average $15 \pm 7 \mathrm{~mm} \mathrm{Hg}$ (range 5-33 $\mathrm{mm} \mathrm{Hg}$ ); see Table 2 . In the remaining 15 patients (group B), the average value of SAP remained almost unchanged or it even decreased (108 \pm 16 vs. $104 \pm 17 \mathrm{~mm} \mathrm{Hg}, p=0.05)$. We therefore, analyzed the two groups $\mathrm{A}$ and B, separately. A summary of the parameters obtained on both groups is reported in Table 2. In group A we observed a significant increase in LF power in SAP and DAP variability during tilt, and in HF power in SAP, with no difference in central frequency of both spectral components.

On the contrary, no significant differences were found in group B, with the exception of a significant increase in the HF power in DAP variability.

\section{Discussion}

Head-up tilt is one of the most employed experimental stimuli for the assessment of the homeostatic response to a cardiovascular stressor challenge (Cooke et al., 1999; Furlan et al., 2000; Montano et al., 1994; Pagani et al., 1986). The caudal shift of blood, and the consequent reduc-tion of venous return, triggers a compensatory baroreflex-mediated increase of heart rate and peripheral vascular resistance aiming at maintaining arterial pressure into a physiological range (Robertson et al., 2012). Systolic and diastolic pressures have been shown to increase during head-up tilt in normal subjects (Cooke et al., 1999; Porta et al., 2012).

The first novel finding of our study is that not all patients with $\mathrm{AF}$ experienced an increase of systolic pressure during tilt: 15 out of 30 patients had blood pressure values that remained almost unchanged or it even slightly decreased. When considering the study population in relation to the presence or absence of a pressor response to tilt no substantial clinical difference could be found between the two groups (group A: patients whose systolic arterial pressure increased during tilt, group B: patients whose systolic arterial pressure did not increase during tilt). Nevertheless, some tendencies were observed: patients of group A were on average younger ( $61 \pm 15$ vs. $67 \pm 9$ years, ns; group A vs. group B) than those of group B, their ejection fraction smaller ( $55 \pm 9$ vs. $60 \pm 6 \%$, ns; group A vs. group B) and a shorter mean RR at rest and tilt (rest: $747 \pm 155$ vs. $769 \pm 185 \mathrm{~ms}$, ns; tilt $690 \pm 141$ vs. $710 \pm 167 \mathrm{~ms}$, ns; group A vs. group B). No differences were instead present in relation to use of drugs known to affect cardiovascular response to tilt such as beta-blockers or amiodarone.

When assessing autonomic response of heart rate and blood pressure to head-up tilt test, frequency domain analysis is the most commonly used technique (Arai et al., 1999; Montano et al., 1994; Mukai and Hayano, 1985; Pagani et al., 1986; Pancera et al., 1999; Piccirillo et al., 1995). This approach, however, is almost precluded in AF patients for the irregularity of the RR interval time series. In fact, during AF when 
(a)

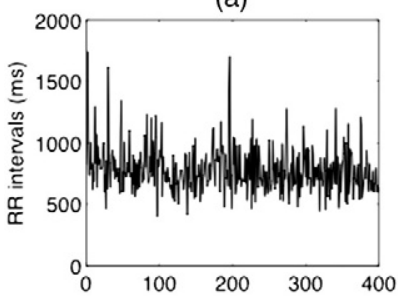

(d)

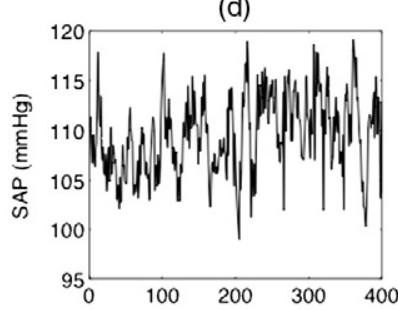

(g)

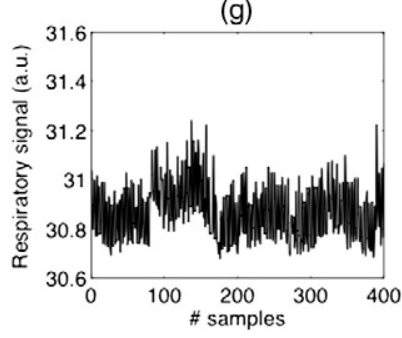

(b)

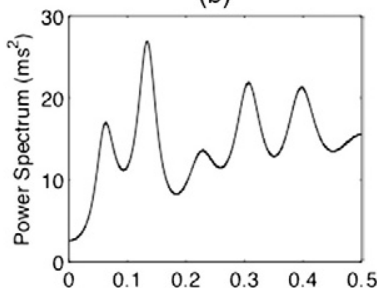

(e)

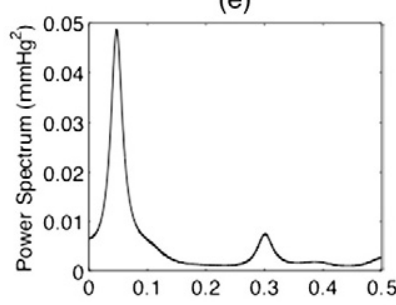

(h)

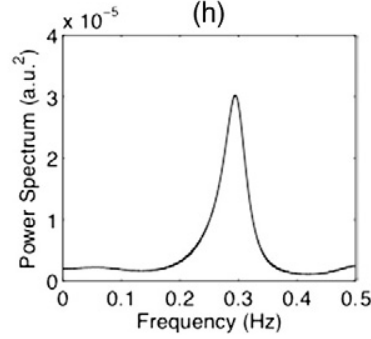

(c)

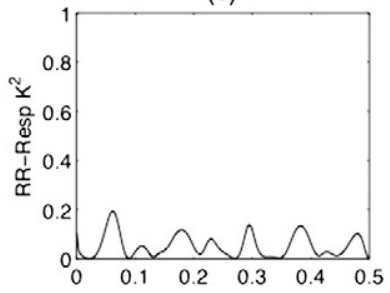

(f)

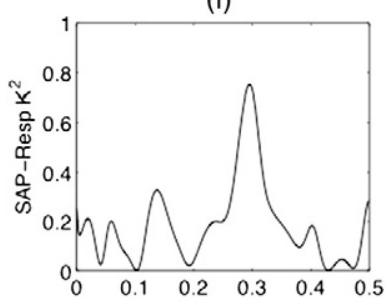

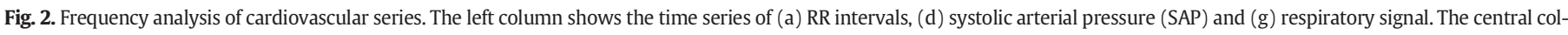

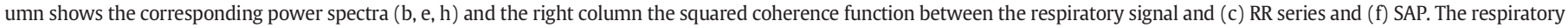
signal visibly modulates the systolic arterial pressure, as can be noted from the high peak of coherence corresponding to the peak of the respiratory signal.

the variability of RR series is analyzed with spectral techniques, a white noise pattern without any identifiable discrete components along the frequency axis becomes evident. When considering instead arterial

\section{Table 2}

Time domain pressure and RR series variables during rest and tilt in the two subpopulations.

\begin{tabular}{|c|c|c|c|}
\hline & & Rest & Tilt \\
\hline \multicolumn{4}{|c|}{ Group A } \\
\hline \multirow[t]{5}{*}{ SAP } & Mean (mm Hg) & $98 \pm 16$ & $114 \pm 18(15)^{*}$ \\
\hline & $\operatorname{Freq}_{\mathrm{LF}}(\mathrm{Hz})$ & $0.07 \pm 0.03$ & $0.08 \pm 0.04(12)$ \\
\hline & $\operatorname{PoW}_{\mathrm{LF}}\left(\mathrm{mm} \mathrm{Hg}{ }^{2}\right)$ & $2.24 \pm 2.75$ & $6.60 \pm 5.11^{*}(12)$ \\
\hline & Freq $_{\mathrm{HF}}(\mathrm{Hz})$ & $0.30 \pm 0.05$ & $0.29 \pm 0.07(15)$ \\
\hline & $\operatorname{Pow}_{\mathrm{HF}}\left(\mathrm{mm} \mathrm{Hg}^{2}\right)$ & $1.80 \pm 1.85$ & $3.80 \pm 3.72^{*}(15)$ \\
\hline \multirow[t]{5}{*}{ DAP } & Mean $(\mathrm{mm} \mathrm{Hg})$ & $70 \pm 14$ & $87 \pm 13^{*}(15)$ \\
\hline & $\operatorname{Freq}_{\mathrm{LF}}(\mathrm{Hz})$ & $0.07 \pm 0.03$ & $0.08 \pm 0.03$ \\
\hline & $\operatorname{Pow}_{\mathrm{LF}}\left(\mathrm{mm} \mathrm{Hg}{ }^{2}\right)$ & $3.54 \pm 1.95$ & $4.38 \pm 3.21^{*}(11)$ \\
\hline & Freq $_{\mathrm{HF}}(\mathrm{Hz})$ & $0.27 \pm 0.05$ & $0.28 \pm 0.07(15)$ \\
\hline & $\operatorname{Pow}_{\mathrm{HF}}\left(\mathrm{mm} \mathrm{Hg}^{2}\right)$ & $1.82 \pm 0.68$ & $2.15 \pm 1.25(15)$ \\
\hline \multicolumn{4}{|c|}{ Group B } \\
\hline \multirow[t]{5}{*}{ SAP } & Mean (mm Hg) & $108 \pm 16$ & $104 \pm 17(15)^{*}$ \\
\hline & $\operatorname{Freq}_{\mathrm{LF}}(\mathrm{Hz})$ & $0.08 \pm 0.04$ & $0.09 \pm 0.04(15)$ \\
\hline & $\operatorname{Pow}_{\mathrm{LF}}\left(\mathrm{mm} \mathrm{Hg}{ }^{2}\right)$ & $4.60 \pm 3.39$ & $6.83 \pm 6.17(15)$ \\
\hline & Freq $_{\mathrm{HF}}(\mathrm{Hz})$ & $0.28 \pm 0.05$ & $0.30 \pm 0.04(14)$ \\
\hline & $\operatorname{Pow}_{\mathrm{HF}}\left(\mathrm{mm} \mathrm{Hg}^{2}\right)$ & $2.07 \pm 1.30$ & $2.42 \pm 1.62(14)$ \\
\hline \multirow[t]{5}{*}{ DAP } & Mean (mm Hg) & $78 \pm 18$ & $79 \pm 15(15)$ \\
\hline & Freq $_{\mathrm{LF}}(\mathrm{Hz})$ & $0.07 \pm 0.02$ & $0.07 \pm 0.03(12)$ \\
\hline & $\operatorname{Pow}_{\mathrm{LF}}\left(\mathrm{mm} \mathrm{Hg}{ }^{2}\right)$ & $4.26 \pm 1.80$ & $4.61 \pm 2.16(12)$ \\
\hline & Freq $_{\mathrm{HF}}(\mathrm{Hz})$ & $0.30 \pm 0.06$ & $0.29 \pm 0.08(15)$ \\
\hline & $\operatorname{Pow}_{\mathrm{HF}}\left(\mathrm{mm} \mathrm{Hg}^{2}\right)$ & $1.92 \pm 0.88$ & $2.63 \pm 1.60^{*}(15)$ \\
\hline
\end{tabular}

Data are expressed as mean \pm one SD (number averaged subjects); SAP = systolic arterial pressure, DAP = diastolic arterial pressure, group A: patients whose systolic arterial pressure increased during tilt, group B: patients whose systolic arterial pressure did not increase during tilt.

$* p<0.05$. pressure variability, we have recently shown (Corino et al., 2010; Mainardi et al., 2009) the presence of a LF component of systolic blood pressure variability in patients with $\mathrm{AF}$, thus proving that the $0.1 \mathrm{~Hz}$ oscillatory component of systolic blood pressure variability might be present in the absence of a correspondent fluctuation in the RR interval time series. This finding reflected, in our opinion, the capability of autonomic nervous system in generating LF oscillations in blood pressure even in the presence of an irregular ventricular electrical and mechanical activity. In the present study, all patients but four had a LF component in SAP series; the four patients not showing a LF component had a lower mean RR interval compared to the others and we can-not rule out that this might have affected stroke volume and pulse pressure thus making the physiological oscillations in SAP variability less detectable.

The second finding of this study is that the LF component of blood pressure variability in patients with AF increases its amplitude in response to the sympathetic stimulation induced by tilt (Langhorst et al., 1983). This increase was present especially in those patients whose vascular regulatory mechanisms appear efficient (group A, i.e., patients that experienced an increase of systolic pressure during tilt). This finding, reported for the first time, is, in our opinion, consistent with the hypothesis that $0.1 \mathrm{~Hz}$ oscillations of arterial pressure variability may be directly modulated by sympathetic activity controlling vascular resistance and further support the concept of a central neural origin of these oscillations traditionally defined as Mayer waves (Langhorst et al., 1983). In fact in patients with AF, the hypothesis suggesting that LF may be generated by a resonance phenomenon of the sympathetic control loop of the baroreflex (Akselrod et al., 1985; de Boer et al., 1985) appears unlikely. On the other hand, being that $0.1 \mathrm{~Hz}$ rhythmicity well detectable in the neural network of reticular formation (Langhorst et al., 1983) it is possible that when its activity is synchronized with that of vascular smooth muscle, arterial pressure waves 
may present oscillation that can be detected in the $0.1 \mathrm{~Hz}$ frequency range. This effect has been described in the past as a resonance phenomenon, mediated by sympathetic discharge and, in the present experiments, amplified during sympathetic activation induced by tilt.

When comparing the extent of these oscillations in comparison to that observed in subjects in sinus rhythm, we found in AF patients, a LF component power slightly smaller than that of subjects in sinus rhythm (Laitinen et al., 2004) either at rest or in response to tilt (4.00 \pm 3.14 to $6.79 \pm 5.70 \mathrm{~mm} \mathrm{Hg}^{2}$ during rest and tilt respectively). It is well known that the power of LF component of arterial pressure var-iability and its response to tilt is affected by aging (Chern et al., 1999; Laitinen et al., 2004; Piccirillo et al., 2004). We cannot rule out, however, that in AF patients, the absence of physiological and effective baroreflex mechanisms might have contributed to determine a smaller amplitude of LF oscillations of arterial pressure variability at rest and during tilt.

As to the presence of HF in SAP and DAP variability, it has to be recalled that our findings are in agreement with previous observations of Pitzalis et al. (1999), who described a respiration related HF component in SAP variability during AF. These authors also evaluated whether synchronous variations in SAP and respiration could depend on a simultaneous change in heart rate. During $\mathrm{AF}$ and under controlled breathing, they found a modest degree of coherence between respiration and heart rate whereas the coherence between respiration and arterial pressure was elevated. Our results obtained during free breathing in both rest and tilt phases showed a HF component in both variability signals with a significant degree of coherence during AF.

In conclusion, these results suggest that also in the absence of a functional sympathetic control loop of the baroreflex, the oscillatory components of sympathetic discharge in the brain are instrumental for determining the $0.1 \mathrm{~Hz}$ oscillations of systolic and diastolic arterial pressure and may contribute to a better description of the mechanisms responsible of its variability during AF.

\section{Conflict of interest}

None declared.

\section{References}

Akaike, H., 1998. Statistical predictor identification. In: Parzen, E., Tanabe, K., Kitagawa, G. (Eds.), Selected Papers of Hirotugu Akaike. Springer Series in Statistics. Springer, New York, pp. 137-151.

Akselrod, S., Gordon, D., Madwed, J.B., Snidman, N.C., Shannon, D.C., Cohen, R.J., 1985 He- modynamic regulation: investigation by spectral analysis. Am. J. Physiol. Heart Circ. Physiol. 249, H867-H875.

Arai, H., Sato, H., Yamamoto, M., Uchida, M., Nakamachi, T., Kaneko, T., Arikawa, T. Tsuboko, Y., Aizawa, T., Iinuma, H., Kato, K., 1999. Changes in the fractal component of spectral analysis of heart rate variability and systolic blood pressure variability dur-ing the head-up tilt test. J. Cardiol. 34, 211-217.

Baselli, G., Cerutti, S., Civardi, S., Lombardi, F., Malliani, A., Merri, M., Pagani, M., Rizzo, G., 1987. Heart rate variability signal processing: a quantitative approach as an aid to diagnosis in cardiovascular pathologies. Int. J. Biomed. Comput. 20, 51-70. Camm, A.J., Kirchhof, P., Lip, G.Y.H., Schotten, U., Savelieva, I., Ernst, S., Gelder, I.C.V.

Al- Attar, N., Hindricks, G., Prendergast, B., Heidbuchel, H., Alfieri, O., Angelini, A., Atar, D., Colonna, P., Caterina, R.D., Sutter, J.D., Goette, A., Gorenek, B., Heldal, M., Hohloser, S.H., Kolh, P., Heuzey, J.-Y.L., Ponikowski, P., Rutten, F.H., Vahanian, A Auricchio, A., Bax, J., Ceconi, C., Dean, V., Filippatos, G., Funck-Brentano, C., Hobbs, R. Kearney, P., McDonagh, T., Popescu, B.A., Reiner, Z., Sechtem, U., Sirnes, P.A., Tendera, M., Vardas, P.E., Widimsky, P., Vardas, P.E., Agladze, V., Aliot, E., Balabanski, T. Blomstrom-Lundqvist, C., Capucci, A., Crijns, H., Dahlöf, B., Folliguet, T., Glikson, M., Goethals, M., Gulba, D.C., Ho, S.Y., Klautz, R.J.M., Kose, S., McMurray, J., Filardi, P.P., Raatikainen, P., Salvador, M.J., Schalij, M.J., Shpektor, A., Sousa, J., Stepinska, J., Uuetoa
H., Zamorano, J.L., Zupan, I., 2010. Guidelines for the management of atrial fibrillation The Task Force for the Management of Atrial Fibrillation of the European Society of Cardiology (ESC). Eur. Heart J. 31, 2369-2429. http://dx.doi.org/10.1093/ eurheartj/ehq278.

Chern, C.-M., Kuo, T.B.-J., Sheng, W.-Y., Wong, W.-J., Luk, Y.-O., Hsu, L.-C., Hu, H.-H., 1999. Spectral analysis of arterial blood pressure and cerebral blood flow velocity during supine rest and orthostasis. J. Cereb. Blood Flow Metab. 19, 1136-1141. http://dx doi.org/10.1097/00004647-199910000-00010.

Cooke, W.H., Hoag, J.B., Crossman, A.A., Kuusela, T.A., Tahvanainen, K.U.O., Eckberg, D.L., 1999. Human responses to upright tilt: a window on central autonomic integration. J. Physiol. 517, 617-628. http://dx.doi.org/10.1111/ j.1469-7793.1999.0617t.x

Corino, V.D.A., Lombardi, F., Mainardi, L.T., 2010. On the reliability of frequency components in systolic arterial pressure in patients with atrial fibrillation. Med. Biol. Eng. Comput. 48, 381-387. http://dx.doi.org/10.1007/s11517-010-0588-z. Corino, V.D.A., Mainardi, L.T., Lombardi, F., 2013. Spectral analysis of blood pressure variability in atrial fibrillation: the effect of tilting. Computing in Cardiology Conference (CinC), 2013. Presented at the Computing in Cardiology Conference (CinC), 2013, pp. 1203-1206.

de Boer, R.W., Karemaker, J.M., Strackee, J., 1985. Relationships between short-term blood-pressure fluctuations and heart-rate variability in resting subjects II: a simple model. Med. Biol. Eng. Comput. 23, 359-364. http://dx.doi.org/10.1007/BF02441590. Furlan, R., Porta, A., Costa, F., Tank, J., Baker, L., Schiavi, R., Robertson, D., Malliani, A., Mosqueda-Garcia, R., 2000. Oscillatory patterns in sympathetic neural discharge and cardiovascular variables during orthostatic stimulus. Circulation 101, 886892. http://dx.doi.org/10.1161/01.CIR.101.8.886.

Kay, S.M., Marple, S.L.J., 1981. Spectrum analysis \#8212; a modern perspective. Proc. IEEE 69, 1380-1419. http://dx.doi.org/10.1109/PROC.1981.12184.

Laitinen, T., Niskanen, L., Geelen, G., Länsimies, E., Hartikainen, J., 2004. Age dependency of cardiovascular autonomic responses to head-up tilt in healthy subjects. J. Appl.

Physiol. 96, 2333-2340. http://dx.doi.org/10.1152/japplphysiol.00444.2003. Langhorst, P., Schulz, B., Schulz, G., Lambertz, M., Krienke, B., 1983. Reticular formation of

the lower brainstem. A common system for cardiorespiratory and somatomotor func-tions: discharge patterns of neighboring neurons influenced by cardiovascular and respiratory afferents. J. Auton. Nerv. Syst. 9, 411-432. http:// dx.doi.org/10.1016/0165-1838(83)90005-X.

Mainardi, L., Corino, V., Belletti, S., Terranova, P., Lombardi, F., 2009. Low frequency component in systolic arterial pressure variability in patients with persistent atrial fibril-lation. Auton. Neurosci. 151, 147-153. http://dx.doi.org/10.1016/ j.autneu.2009.06. 008

Montano, N., Ruscone, T.G., Porta, A., Lombardi, F., Pagani, M., Malliani, A., 1994. Power spectrum analysis of heart rate variability to assess the changes in sympathovagal balance during graded orthostatic tilt. Circulation 90, 1826-1831. http:// dx.doi.org/ 10.1161/01.CIR.90.4.1826.

Mukai, S., Hayano, J., 1995. Heart rate and blood pressure variabilities during graded head-up tilt. J. Appl. Physiol. Bethesda Md 78, 212-216.

Pagani, M., Lombardi, F., Guzzetti, S., Rimoldi, O., Furlan, R., Pizzinelli, P., Sandrone, G., Malfatto, G., Dell'Orto, S., Piccaluga, E., 1986. Power spectral analysis of heart rate and arterial pressure variabilities as a marker of sympatho-vagal interaction in man and conscious dog. Circ. Res. 59, 178-193. http://dx.doi.org/10.1161/01.RES.59.2.178.

Pancera, P., Presciuttini, B., Sansone, S., Montagna, L., Paluani, F., Covi, G., Lechi, A.,

1999. Effect of losartan on heart rate and blood pressure variability during tilt test

and trinitroglycerine vasodilation. J. Hypertens. 17, 513-521.

Piccirillo, G., Fimognari, F.L., Viola, E., Marigliano, V., 1995. Age-adjusted normal confidence intervals for heart rate variability in healthy subjects during head-up tilt. Int. J. Cardiol. 50, 117-124. http://dx.doi.org/10.1016/0167-5273(95)93680-Q.

Piccirillo, G., Naso, C., Moisè, A., Lionetti, M., Nocco, M., Di Carlo, S., De Laurentis, T., Magrì, D., Cacciafesta, M., Marigliano, V., 2004. Heart rate and blood pressure variability in subjects with vasovagal syncope. Clin. Sci. 107, 55. http:// dx.doi.org/10.1042/CS20030327.

Pitzalis, M.V., Massari, F., Forleo, C., Fioretti, A., Colombo, R., Balducci, C., Mastropasqua, F., Rizzon, P., 1999. Respiratory systolic pressure variability during atrial fibrillation and sinus rhythm. Hypertension 34, 1060-1065. http:// dx.doi.org/10.1161/01.HYP.34.5. 1060.

Porta, A. Bassani, T. Bari, V. Tobaldini, E. Takahashi, A.C.M. Catai, A.M., Montano, N. 2012. Model-based assessment of baroreflex and cardiopulmonary couplings during graded head-up tilt. Comput. Biol. Med. 42, 298-305. http:// dx.doi.org/10.1016/j. compbiomed.2011.04.019 (Computing complexity in cardiovascular oscillations Selected Papers from the 6th ESGCO conference).

Robertson, D., Diedrich, A., Chapleau, M.W., 2012. Editorial on arterial baroreflex issue. Auton. Neurosci 172, 1-3. http://dx.doi.org/10.1016/j.autneu.2012.10.010 (Arterial Baroreflex).

Stein, K.M., Walden, J., Lippman, N., Lerman, B.B., 1999. Ventricular response in atrial fibrillation: random or deterministic? Am. J. Physiol. Heart Circ. Physiol. 277, H452-H458 